\title{
Optimization of the culture medium composition using response surface methodology for new recombinant cyprosin B production in bioreactor for cheese production
}

\author{
Pedro N. Sampaio • Cecília R. C. Calado \\ Lisete Sousa • David C. Bressler • Maria Salome' Pais • Luıs Pina Fonseca
}

\section{P. N. Sampaio \& M. S. Pais}

BioFIG, Unit of Molecular Biology \& Plant Biotechnology,

Plant Systems Biology Laboratory, Institute of Applied Science and Technology, Faculty of Sciences of University of Lisbon,

Campo Grande, 1749-016 Lisbon, Portugal

\section{P. N. Sampaio \& L. P. Fonseca}

Institute of Biotechnology and Bioengineering,

Chemical and Biological Engineering Center,

Instituto Superior Te'cnico, Av. Rovisco Pais,

1049-001 Lisbon, Portugal

\section{R. C. Calado}

Faculty of Engineering, Catholic University of Portugal,

Estrada Octávio Pato, 2635-631 Rio de Mouro, Portugal

\section{Sousa}

Department of Statistics and Operations Research,

Center of Statistics and Applications (CEAUL),

Faculty of Sciences of University of Lisbon,

1749-016 Lisbon, Portugal

\section{C. Bressler}

Agricultural, Food and Nutritional Science Department, Faculty of Agricultural, Life \& Environmental Sciences, University of Alberta, 410 Agriculture Forestry Bldg, Edmonton, AB T6G 2P5, Canada 


\begin{abstract}
The optimization of culture medium composition was carried out for improvement the recombinant cyprosin B production, an enzyme with high milk-clotting activity. Response surface methodology (RSM) was applied to evaluate the effect of variables namely glucose, yeast extract (YE) and bactopeptone present in the culture medium, used for recombinant cyprosin B production by transformed Saccharomyces cerevisiae BJ1991 strain in shake-flask and bioreactor culture conditions. The central composite experimental design (CCD) was adopted to derive a statistical model for optimizing the composition of the fermentation medium. The optimal concentration estimated for each variable related to a theoretical maximum of cyprosin $B$ activity $\left(488 \mathrm{U} \mathrm{mL}^{-1}\right)$ was $30 \mathrm{~g}$ $\mathrm{L}^{-1}$ glucose, $15 \mathrm{~g} \mathrm{~L}^{-1} \mathrm{YE}$ and $27 \mathrm{~g} \mathrm{~L}^{-1}$ bactopeptone. The optimized medium composition, based on empirical model, led to a cyprosin B activity of $519 \mathrm{U} \mathrm{mL}^{-1}$, which corresponds to an increase of $46 \%$. The fermentation using optimized culture medium in a 5- $\mathrm{L}$ bioreactor allowed a significant increase in biomass (82\%) and recombinant cyprosin B production (139\%). The improvement in the recombinant cyprosin B production after optimization process can be considered adequate for largescale applications, and the clotting activity of cyprosin B account for their use in industrial cheese making.
\end{abstract}

Keywords: Culture media composition, Cyprosin B, Fermentation, Response surface methodology, Saccharomyces cerevisiae 


\section{Introduction}

Cyprosin B is an aspartic protease present in the pistils of Cynara cardunculus, with great potential for cheese production due to its high clotting activity [1]. The $S$. cerevisiae BJ1991 strain was transformed by CYPRO11 gene [2], which codifies for cyprosin B (International patent WO 00/75283, PCT/PT00/00007). The expression of CYPRO11 gene is controlled by GAL7 promoter which is inducible by galactose present in the culture medium. Studies on the expression and characterization of recombinant cyprosin $B$ in bioreactor were previously carried out using transformed $S$. cerevisiae W303-1A, proving that active cyprosin B is efficiently expressed and secreted to the extracellular medium, having the ability for clotting milk [3].

The biochemical and nutritional cell environment in a bioreactor is strongly influenced by growth conditions and medium composition, namely carbon and nitrogen sources, mineral salts, trace elements, peptides, amino acids, vitamins and/or other factors. Therefore, the optimization of culture medium composition is essential for the effective production in bioreactor $[4,5]$. The production of biomolecules, such as enzymes for food industry, often requires the use of complex and cheap industrial media based on yeast extract (YE) and bactopeptone as nitrogen sources. Complex organic nitrogen sources are less expensive than pure amino acids and nitrogen bases and, additionally, can supply a variety of vitamins, minerals and other growth co-factors. Furthermore, cell growth is generally more rapid and efficient when these nutrients are used, since they reduce the number of components that cells would otherwise have to synthesize de novo. A widely used complex rich growth medium containing YE and bactopeptone as nitrogen sources and glucose as carbon source played an important role in the efficiency and economics of the fermentation process [6]. The activity and stability of enzymes is influenced by the type of strain, cultivation conditions (temperature, $\mathrm{pH}$, aeration, agitation, incubation time) and culture medium composition (particularly carbon and nitrogen sources) [7-9].

RSM is a mathematical and statistical technique for building empirical models that gained importance for optimizing production conditions of industrially high value products such as chemicals and enzymes and for studying enzyme kinetics. In this methodology, multivariate experiments are designed to reduce the number of assays necessary to optimize the process and to gather results more precise than those obtainable by univariate strategies. This statistical tool has been used in many biotechnological processes namely optimization of culture conditions [10-13]; enzyme 
production [14, 15]; ethanol production [16, 17] and biomass production [18]. This statistical tool was also useful for optimization of recombinant products yields such as actinorhodin [19]; nisin [13]; lysozyme [20]; alkaline protease [12]; hirudin [21] as well as extracellular polysaccharose and biomass [22].

The aim of this work was to improve the production of recombinant cyprosin $B$ by transformed S. cerevisiae BJ1991 strain applying the RSM tool for the optimization of culture medium composition's (glucose, YE and bactopeptone) concentrations maintaining the inducer concentration (galactose) constant. These optimal experimental results were confirmed by shake-flask and bioreactor culture, and, furthermore, biochemical and milk-clotting studies were performed for process characterization.

\section{Materials and methods}

Microorganism

S. cerevisiae BJ1991 strain (MATa leu2, trp1, ura3-52, prb1-1122, pep4-3) was transformed previously with episomal plasmid (pCAF15), containing CYPRO11 gene (International patent WO 00/75283, PCT/PT00/00007). The stock of transformed cells was maintained in glycerol $50 \%(\mathrm{v} / \mathrm{v})$ at $-80 \stackrel{\circ}{ } \mathrm{C}$.

\section{Inoculum and culture conditions}

YNB medium [0.67\% (w/v) yeast nitrogen base without amino acids (Sigma, Germany) and $2 \%(w / v)$ glucose (Merck, Germany)], supplemented with auxotrophics markers (70 $\mathrm{mg} \mathrm{L}^{-1}$ tryptophan and $20 \mathrm{mg} \mathrm{L}^{-1}$ uracil), previously sterilized by microfiltration, was used as inoculum for S. cerevisiae BJ1991 culture [23]. The inoculum, containing 50 $\mathrm{mL}$ of YNB medium, was grown for $16 \mathrm{~h}$ in $200 \mathrm{~mL}$ shake-flasks maintained in an orbital shaker $(200 \mathrm{rpm})$ at $30 \stackrel{\circ}{ } \mathrm{C}$ (Aralab, Portugal) till reached the optic density (OD600nm) of the 5.0. The experiments were carried out using shake-flasks $(200 \mathrm{~mL})$ containing $30 \mathrm{~mL}$ of culture medium, during $96 \mathrm{~h}(200 \mathrm{rpm})$ at $30 \stackrel{\circ}{\circ}$ and $1.5 \mathrm{~mL}$ of inoculum in YNB medium. The culture medium is composed of glucose (Merck, Germany), bactopeptone (Difco, USA) and YE (Merck, Germany) at different concentrations according to the experimental design (Table 2). The concentration of galactose (Sigma, Germany) was maintained constant $\left(20 \mathrm{~g} \mathrm{~L}^{-1}\right)$ in all assays.

All culture media were buffered using a $50 \mathrm{mM}$ 2-(Nmorpholino) ethanesulfonic acid (MES) buffer pH 6.0 chosen according to previous studies carried out in shake-flask (data not shown). 


\section{Enzyme production in bioreactor}

The inocula for fermentations (control and optimized conditions) were grown overnight in a shake-flasks $(500 \mathrm{~mL})$ with $150 \mathrm{~mL}$ of $\mathrm{YNB}$ medium, at $30{ }^{\circ} \mathrm{C}$ (200 rpm) till OD600nm (5.0). The fermentations were performed in a 5-L bioreactor (HT-Infors, Bottmingen, Switzerland) containing $3 \mathrm{~L}$ of culture medium at $\mathrm{pH} 6.0$ and $30.0{ }^{\circ} \mathrm{C}$. The original culture medium consists of $10 \mathrm{~g} \mathrm{~L}^{-1} \mathrm{YE}, 20 \mathrm{~g} \mathrm{~L}^{-1}$ bactopeptone, $20 \mathrm{~g} \mathrm{~L}^{-1}$ glucose and $20 \mathrm{~g} \mathrm{~L}^{-1}$ galactose; and for optimal concentrations, $15 \mathrm{~g} \mathrm{~L}^{-1} \mathrm{YE}, 27 \mathrm{~g} \mathrm{~L}^{-1}$ bactopeptone, $30 \mathrm{~g} \mathrm{~L}^{-1}$ glucose and $20 \mathrm{~g} \mathrm{~L}^{-1}$ galactose. The culture medium containing the complex nitrogen sources (YE and bactopeptone) was sterilized in the reaction vessel at $121^{\circ} \mathrm{C}$ for $20 \mathrm{~min}$. The carbon sources (glucose and galactose) were added to complex nitrogen sources after sterilization, using a peristaltic pumping system in sterilized conditions. The bioreactor was inoculated at a $5 \%(\mathrm{v} / \mathrm{v})$ ratio. The oxygen tension was measured as the percentage of dissolved oxygen in the culture medium in relation to air saturation, using an oxygen probe (Ingold, Germany). Along fermentation, the air was supplied at a constant flow rate of $3 \mathrm{~L} \mathrm{~min}^{-1}$ (equivalent to 1 VVM). Mechanical agitation, produced by two Rushton turbines, was automatically controlled by setting the percentage of dissolved oxygen in the culture medium at $50 \%$. The initial $\mathrm{pH} 6.0$ was adjusted automatically during the fermentation by addition of acid $(2 \mathrm{M} \mathrm{HCl})$ and alkali $(2 \mathrm{M} \mathrm{NaOH})$ solutions. The samples were collected under aseptic conditions to analyze the fermentation performance, biomass, protein concentration and enzymatic activity evolution.

\section{Analytical methods}

Biomass determination

Biomass concentration was determined using a spectrophotometer (Shimadzu UV1603, Japan) at an optical density of OD600 nm. Cells were diluted in $0.8 \%(\mathrm{w} / \mathrm{v}) \mathrm{NaCl}$ solution, and absorbance values were converted to dry cell weight (DCW) using a standard curve based on the weight of cell samples dried at $80 \stackrel{\circ}{ } \mathrm{C}$ until constant weight.

\section{Protein concentration}

Protein concentration was determined according to the Bradford method using Coomassie reagent (Bio-Rad Laboratories, Hercules, CA, USA) (Bradford 1976) [24]. Bovine serum albumin (Sigma, Germany) was used as standard. The absorbance was measured in the wavelength at $595 \mathrm{~nm}$ in a spectrophotometer (Shimadzu UV-1603, Japan). 


\section{Enzymatic activity assay}

Enzymatic activity of samples was evaluated using fluorescein isothiocyanate-labeled K-casein (FITC-casein) as the substrate, prepared according to the Twining method [25]. One unit of proteolytic activity was defined as the amount of enzyme that increases one unit of emitted fluorescence at $525 \mathrm{~nm}$ (excitation at $495 \mathrm{~nm}$ ) after $1 \mathrm{~h}$ of hydrolysis at $37^{\circ} \mathrm{C}$ [26]. Fluorescence intensity was measured using a spectrofluorimeter (Shimadzu RF-1501, Japan).

\section{Efficiency of protein secretion}

The biomass pellet collected after centrifugation at $8,5009 \mathrm{~g}$ for 5 min was resuspended and washed twice with $50 \mathrm{mM}$ Tris- $\mathrm{HCl}$ containing $10 \mathrm{mM}$ EDTA pH 8.3 buffer (TE buffer). Cell disruption was performed by vigorous mixing in TE buffer with $50 \%(\mathrm{v} / \mathrm{v})$ $500-\mu \mathrm{m}$ glass spheres (Sigma, Germany) for $5 \mathrm{~min}$ with $1 \mathrm{~min}$ intervals in ice. Cell debris were removed by centrifugation at $8,5009 \mathrm{~g}$ during $15 \mathrm{~min}$ at $4{ }^{\circ} \mathrm{C}$.

\section{Milk-clotting activity}

The clotting assay was carried out by adding $50 \mu \mathrm{L}$ of recombinant cyprosin $\mathrm{B}$, obtained after each fermentation, to $1 \mathrm{~mL}$ of skim milk with $10 \mathrm{mM}$ of $\mathrm{CaCl}_{2}, \mathrm{pH} 6.5$ according to the International Dairy Federation method [27].

\section{Statistical methods}

\section{Experimental design and optimization}

RSM was used to study combined interactions among different physiological variables. The central composite design (CCD) was used to improve recombinant cyprosin B production, considering optimized levels of variables [28]. The substrates glucose $\left(X_{1}\right.$, $\left.\mathrm{g} \mathrm{L}^{-1}\right)$, YE $\left(\mathrm{X}_{2}, \mathrm{~g} \mathrm{~L}^{-1}\right)$ and bactopeptone $\left(\mathrm{X}_{3}, \mathrm{~g} \mathrm{~L}^{-1}\right)$ were chosen as independent variables (Table 1 ). For a $2^{3} \operatorname{CCD}$ with six axial points $\left(\alpha=(3)^{1 / 2}\right)$ and two replicates at the center points of three factors, a set of 16 experiments was carried out. The control medium or original medium, defined by $10 \mathrm{~g} \mathrm{~L}^{-1} \mathrm{YE}, 20 \mathrm{~g} \mathrm{~L}^{-1}$ bactopeptone, $20 \mathrm{~g} \mathrm{~L}^{-1}$ glucose and $20 \mathrm{~g} \mathrm{~L}^{-1}$ galactose (YPGal-Glu medium), was used initially as base for this study. All variables were taken for three different coded levels: $-1,0$ and 1 . The minimum and maximum range, the variables studied and the full experimental plan, with respect to the coded and actual values, are listed in Tables 1 and 2 . The statistical determination of the variable levels Xi was coded as xi according to Eq. 1: 


$$
X_{i}=\left(x_{i}-x_{\mathrm{oi}}\right) / \Delta x_{i} \quad i=0,1,2, \ldots K
$$

where $X_{i}$ is (dimensionless) coded value of the real variable $x_{i}, x_{0}$ is the real value of $X_{i}$ at the center point (zero) level and the $\Delta x_{i}$ is the step change value.

Table 1 Experimental range and levels of independent variables

\begin{tabular}{llcc}
\hline Variables & \multicolumn{3}{c}{ Range of levels (coded/actual) } \\
\cline { 2 - 4 } & -1 & 0 & 1 \\
\hline$\left(X_{1}\right)$ Glucose $\left(\mathrm{g} \mathrm{L}^{-1}\right)$ & 0.0 & 15.0 & 30.0 \\
$\left(X_{2}\right)$ Yeast extract $\left(\mathrm{g} \mathrm{L}^{-1}\right)$ & 5.0 & 10.0 & 15.0 \\
$\left(X_{3}\right)$ Bactopeptone $\left(\mathrm{g} \mathrm{L}^{-1}\right)$ & 5.0 & 17.5 & 30.0 \\
\hline
\end{tabular}


Table 2 Central composite design matrix of independent variables with corresponding experimental and predicted value for cyprosin B activity

\begin{tabular}{|c|c|c|c|c|c|c|c|c|}
\hline \multirow[t]{2}{*}{ Run } & \multicolumn{2}{|l|}{ Glucose $\left(X_{1}\right)$} & \multicolumn{2}{|l|}{$\mathrm{YE}\left(X_{2}\right)$} & \multicolumn{2}{|c|}{ Bactopeptone $\left(X_{3}\right)$} & \multicolumn{2}{|c|}{ Cyprosin B activity $\left(\mathrm{U} \mathrm{mL}^{-1}\right)$} \\
\hline & Actual $\left(\mathrm{g} \mathrm{L}^{-1}\right)$ & Code & Actual $\left(\mathrm{g} \mathrm{L}^{-1}\right)$ & Code & Actual $\left(\mathrm{g} \mathrm{L}^{-1}\right)$ & Code & Experimental & Predicted \\
\hline 1 & 0.0 & -1 & 5.0 & -1 & 5.0 & -1 & 180 & 319 \\
\hline 2 & 0.0 & -1 & 5.0 & -1 & 30.0 & 1 & 176 & 356 \\
\hline 3 & 0.0 & -1 & 15.0 & 1 & 5.0 & -1 & 357 & 474 \\
\hline 4 & 0.0 & -1 & 15.0 & 1 & 30.0 & 1 & 286 & 422 \\
\hline 5 & 30.0 & 1 & 5.0 & -1 & 5.0 & -1 & 255 & 258 \\
\hline 6 & 30.0 & 1 & 5.0 & -1 & 30.0 & 1 & 412 & 434 \\
\hline 7 & 30.0 & 1 & 15.0 & 1 & 5.0 & -1 & 440 & 399 \\
\hline 8 & 30.0 & 1 & 15.0 & 1 & 30.0 & 1 & 487 & 487 \\
\hline 9 & 0.0 & -1.68 & 10.0 & 0 & 17.5 & 0 & 261 & 397 \\
\hline 10 & 40.2 & 1.68 & 10.0 & 0 & 17.5 & 0 & 425 & 400 \\
\hline 11 & 15.0 & 0 & 1.6 & -1.68 & 17.5 & 0 & 359 & 376 \\
\hline 12 & 15.0 & 0 & 18.4 & 1.68 & 17.5 & 0 & 456 & 551 \\
\hline 13 & 15.0 & 0 & 10.0 & 0 & 0.0 & -1.68 & 178 & 270 \\
\hline 14 & 15.0 & 0 & 10.0 & 0 & 38.5 & 1.68 & 356 & 376 \\
\hline 15 & 15.0 & 0 & 10.0 & 0 & 17.5 & 0 & 352 & 418 \\
\hline 16 & 15.0 & 0 & 10.0 & 0 & 17.5 & 0 & 353 & 418 \\
\hline
\end{tabular}


After experiments, the average maximum recombinant cyprosin B activity was taken as the dependent variable or response $(\mathrm{Y})$. A second-order polynomial equation was then fitted to the data by the multiple regression procedure. From this, an empirical model was obtained relating the response evaluated for the independent variables of the experiment. For a four-factor system, the model equation is:

$$
\begin{aligned}
Y= & \beta_{0}+\beta_{1} X_{1}+\beta_{2} X_{2}+\beta_{3} X_{3}+\beta_{12} X_{1} X_{2}+\beta_{13} X_{1} X_{3} \\
& +\beta_{23} X_{2} X_{3}+\beta_{11} X_{1}^{2}+\beta_{22} X_{2}^{2}+\beta_{33} X_{3}^{2}
\end{aligned}
$$

where $\mathrm{Y}$ is the predicted response; $\mathrm{b}_{0}$ is the intercept coefficient; $\mathrm{b} 1, \mathrm{~b} 2$ and $\mathrm{b} 3$ are the linear coefficients: $b_{11}, b_{22}$ and $b_{33}$ are the quadratic coefficients; $b_{12}, b_{13}$ and $b_{23}$ are the interaction coefficients (Eq. 2).

\section{Response surface plot}

The quadratic model obtained from regression analysis allowed to build a threedimensional (3-D) graphic in which the dependent variable $Y$ was represented by a curvature surface as a function of $\mathrm{Xi}$. The relationship between the response and independent variables can be directly visualized from the response surface plot.

The statistical software Design Expert v.8.0.1 (Minneapolis, USA) was used to establish the experimental design and the regression analysis of the experimental data (Table 2). The goodness of fit of the polynomial model equation was expressed by coefficient of determination $\mathrm{R}^{2}$. For the estimated coefficients, it is also possible to calculate Student's t-statistics and associated $P$ values. Experiments were performed in triplicate, and mean values were determined.

\section{Statistical analysis of data}

The recombinant cyprosin B activity was represented by a second-order polynomial equation. The software Design Expert 8.0.1 (Minneapolis, USA) was applied to resolve the regression equation for determination of the maximum cyprosin $B$ activity and the optimal concentrations for each variable. 


\section{Results and discussion}

Optimization of culture medium using statistical analysis the experimental results showed that this mathematical tool can satisfactorily explain the effects of the variables concentration (glucose, YE and bactopeptone) in the recombinant cyprosin B produced by S. cerevisiae BJ1991 strain in shake-flask cultures and in fermenter. The expression and secretion of the recombinant cyprosin B depend on the inducer concentration (galactose), which works also as a carbon source [3]. The maximum enzymatic activity was obtained for the concentration of galactose $\left(40 \mathrm{~g} \mathrm{~L}^{-1}\right)$ in YPGal medium, which has shown to be a straightforward system for regulating and controlling expression of the CYPRO11 gene. Studies performed using the $S$. cerevisiae BJ1991 strain obtained the similar cyprosin B activity with $20 \mathrm{~g} \mathrm{~L}^{-1}$ of galactose (data not shown). As galactose is more expensive than the other components, it was possible to carry out the optimization study using the RSM to determine the optimal concentration of culture medium components and, consequently, to enhance cyprosin B production by transformed S. cerevisiae BJ1991 strain. For optimization using RSM, the variables (YE, bactopeptone and glucose) were considered. To search for the optimum combination of these components in the culture medium, a CCD experimental plan was carried out (Table 2). The results of the second-order response surface model fitting in the form of analysis of variance (ANOVA) are given in Table 3.

Table 3 Analysis of variance (ANOVA) for the selected model ANOVA

\begin{tabular}{lrrrll}
\hline Source & \multicolumn{1}{c}{ SS } & \multicolumn{1}{c}{$d f$} & \multicolumn{1}{c}{ MS } & Fisher test & $P$ value \\
\hline Regression & 140382.6 & 9 & 15598.1 & 7.36 & 0.0123 \\
Residual & 12716.8 & 6 & 2119.5 & & \\
Total & 153099.4 & 15 & & & \\
\hline
\end{tabular}

SS Sum of Squares, $d f$ degrees of freedom, $M S$ mean squares 
The ANOVA analysis, through the quadratic regression model, revealed that the second-order response surface model obtained is highly significant, as it is evident from the high Fisher's test $\left(F_{\text {model }}=\right.$ mean square regression $/$ mean square residual $=$ 7.36) and the low probability value $(P>0.0123)$. A F-test value (7.36) higher than the tabled value $F_{(9,6)}=2.96$ for $10 \%$ significance level representing a significative model. F-test for regression was significant at a level of $10 \%(\mathrm{P}<0.1)$, indicating that the model is appropriate and can adequately explain the variation observed in enzyme biosynthesis with the designed levels of the factors. The $R^{2}$ coefficient obtained, of 0.92 , suggests that it is a reliable model and that $92 \%$ of the sample variation of cyprosin B production is attributed to a high correlation between the independent variables. Only $8 \%$ of the total variation of cyprosin $B$ production is not explained by the model. The relatively high-adjusted determination coefficient $\left(R^{2}{ }_{\text {ddj }}=0: 79\right)$ accounts for a high significance of the model [29]. The coefficient of variation (CV) indicates the degree of precision with which the calculations are compared. Usually, a high CV value represents low reliability of the experiment. The low value obtained ( $C V=13.8 \%$ ) indicates a small residual variability data and the greater reliability of the experiments performed [30].

The $P$ values are used for checking the significance of each coefficient which, in turn, it is necessary to understand the pattern of the mutual interactions between the important variables, where the small magnitude of $P$ values means that the corresponding coefficients are more significant. A positive coefficient represents an effect that favors the optimization of cyprosin B production, while a negative value indicates an antagonistic effect.

The three variables (glucose, YE and bactopeptone), according to the analysis of Table 4 , influencing positively the cyprosin $\mathrm{B}$ biosynthesis, i.e., inside the concentration range evaluated, raised values implied an increase in enzyme biosynthesis, which showed high significance on regression coefficients with the low $P$ value $<0.1\left(P_{X_{1}}=0.0022\right.$; $P_{X 2}=0.0059$ and $\left.P_{X 3}=0.0454 ; P_{X 13}=0.0759 ; P_{X 3,2}=0.0684\right)$. The glucose had more influence than yeast extract and bactopeptone, which proof that yeast has more affinity for glucose for metabolic growth. This affinity for glucose proves that sugar is easily metabolizable by the yeast $S$. cerevisiae because it directly enters the glycolytic pathway as glucose-6-phosphate by the specific transporters [31]. The bactopeptone and the yeast extract, as nitrogen sources, are constituted by essential nutrients for the yeast cell growth and function as the precursors of biomolecules that are fundamentals to the development of the microorganism [32]. 
The bactopeptone had too high significance at the quadratic level $P_{X_{32}}=0.0684$. According to the corresponding regression coefficient, (-33.5) showed a negative effect on enhancing cyprosin $B$ activity, which means that the raise of quadratic directly influenced the decrease in recombinant cyprosin $B$ production. The interaction between glucose and bactopeptone $\left(P_{X_{1 \times 3}}=0.0759\right)$ had too high significance over cyprosin $B$ biosynthesis. Relative to regression coefficient, (34.8) showed a positive influence over cyprosin B production. According to this statistical analysis, the variables studied can act as limiting nutrients, and a slight variation registered in their concentration induces small changes over recombinant cyprosin B production.

Table 4 The least squares fit and parameter estimates (significance of regression coefficient)

\begin{tabular}{lclrl}
\hline Model term & $\begin{array}{l}\text { Regression } \\
\text { coefficient }\end{array}$ & $\begin{array}{l}\text { Standard } \\
\text { error }\end{array}$ & \multicolumn{1}{l}{$t(1)$} & $P$ value \\
\hline Mean interaction & 353.9 & 32.49 & 10.900 & 0.0123 \\
$X_{1}$ & 63.8 & 12.47 & 5.107 & 0.0022 \\
$X_{1}^{2}$ & -6.7 & 15.14 & -0.453 & 0.6745 \\
$X_{2}$ & 52.0 & 52.05 & 12.473 & 0.0059 \\
$X_{2}^{2}$ & 16.1 & 15.14 & 1.059 & 0.3273 \\
$X_{3}$ & 31.4 & 12.47 & 2.515 & 0.0454 \\
$X_{3}^{2}$ & -33.5 & 15.14 & -2.221 & 0.0684 \\
$X_{1} X_{2}$ & -3.4 & 16.30 & -0.208 & 0.8426 \\
$X_{1} X_{3}$ & 34.8 & 16.30 & 2.134 & 0.0759 \\
$X_{2} X_{3}$ & -22.1 & 16.30 & -1.357 & 0.2229 \\
\hline
\end{tabular}


The empirical relationship between recombinant cyprosin $\mathrm{B}$ production $(\mathrm{Y})$ and the experimental variables obtained by the application of the RSM is represented mathematically by the following equation (Eq. 3):

$$
\begin{aligned}
Y= & 353.87+63.76 X_{1}+52.00 X_{2}+31.37 X_{3} \\
& -3.38 X_{1} X_{2}+34.88 X_{1} X_{3}-22.13 X_{2} X_{3} \\
& -6.67 X_{1}^{2}+16.13 X_{2}^{2}-33.54 X_{3}^{2}
\end{aligned}
$$

where $Y$ is the response for the recombinant cyprosin $B$ activity; $X_{1}, X_{2}$ and $X_{3}$ represent the variables glucose, YE and bactopeptone, respectively.

The regression equation was represented in 3-D response surface plots, and each contour curve corresponds to an infinite number of combinations between two test variables, while the third is maintained in optimal concentration. The yield for different concentrations of the variables can also be predicated from the respective response surface plots (Fig. 1a-c). The maximum predicted yield is indicated by the surface confined in the response surface diagram.

The response surface from YE-glucose interaction plot (Fig. 1a) revealed that the increase in the recombinant cyprosin $B$ activity is related to high concentration of $Y E$ $\left(15 \mathrm{~g} \mathrm{~L}^{-1}\right)$ and glucose $\left(30 \mathrm{~g} \mathrm{~L}^{-1}\right)$. For the bactopeptone- glucose interaction plot (Fig. $1 b)$, the high cyprosin $B$ activity is related to the range of optimal concentrations of bactopeptone (15-30 $\left.\mathrm{g} \mathrm{L}^{-1}\right)$ and of glucose $\left(20\right.$ and $\left.30 \mathrm{~g} \mathrm{~L}^{-1}\right)$. The bactopeptone-YE interaction plot (Fig. 1C), which shows high cyprosin B activity, was achieved for the 10-15 $\mathrm{g} \mathrm{L}^{-1}$ for $\mathrm{YE}$, and for bactopeptone concentrations between 20 and $30 \mathrm{~g} \mathrm{~L}^{-1}$. These data confirmed that the optimal values for each variable were within concentration range that corresponds to high cyprosin B activity. In general, cyprosin B production increases with high glucose concentration. 

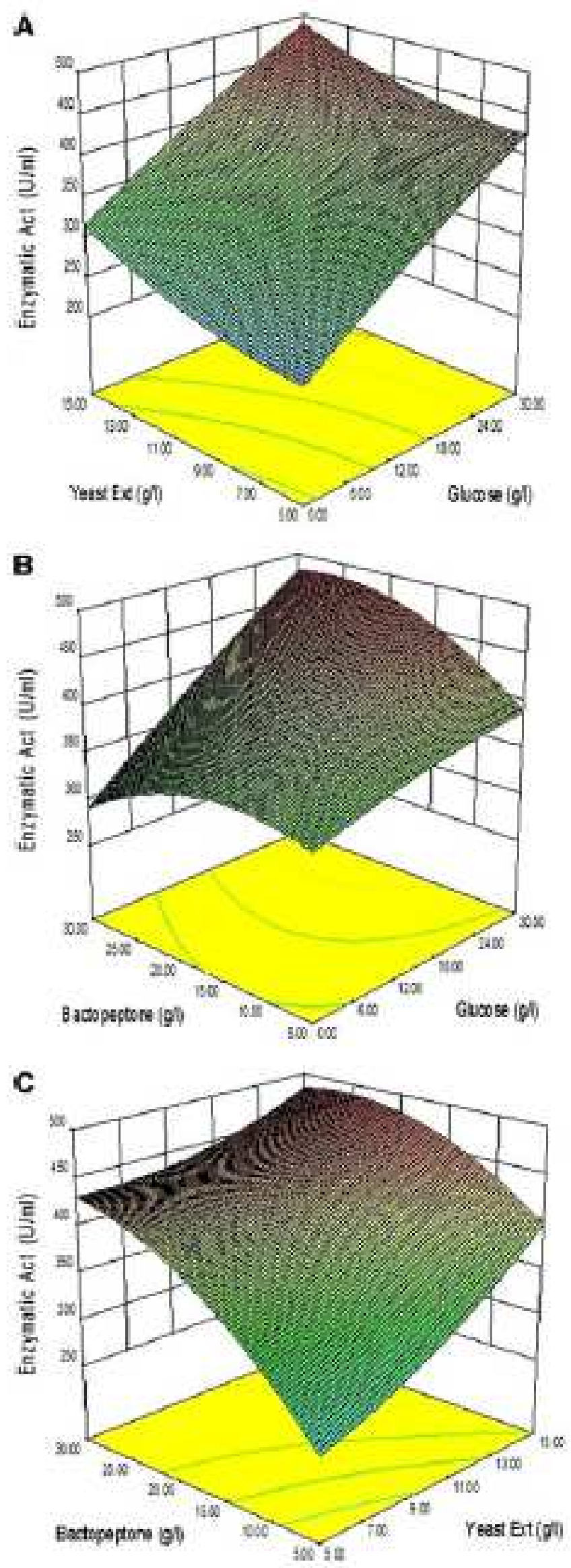

Fig. 1 Plots of response surface of recombinant cyprosin B activity with the fixed parameers: a bactopeptone; b YE and c glucose concentrations at the ir optimum points 
The regression equation, maximized by the Design Expert v.8.0.1 (Minneapolis, USA) software, allowed to obtain the following optimal coded units for test variables: $X_{1}=$ $0.97 ; X_{2}=1.00$ and $X_{3}=0.75$, which corresponds to optimum concentrations of $30 \mathrm{~g} \mathrm{~L}^{-1}$ glucose, $15 \mathrm{~g} \mathrm{~L}^{-1} \mathrm{YE}$ and $27 \mathrm{~g} \mathrm{~L}^{-1}$ bactopeptone, for the maximal recombinant cyprosin $\mathrm{B}$ activity of the $488 \mathrm{U} \mathrm{mL}^{-1}$, predicted by the mathematical model with a high model accuracy (90\%).

Validation experiments were carried out to verify the accuracy of the models, and the results showed that the predicted values are according to the experimental results. The model validation was carried out in shake-flask culture, and using the optimal concentrations of culture medium components has resulted in a cyprosin B activityof $519 \mathrm{U} \mathrm{mL}^{-1}$, representing an increase of $46 \%$, comparatively with the original medium $\left(357 \mathrm{U} \mathrm{mL}^{-1}\right)$ and an increase of the $16 \%$ for biomass.

\section{Bioreactor cultivation}

The predicted optimal medium composition was applied to $S$. cerevisiae BJ1991 cultivation in a $5-L$ bench fermenter for the production of recombinant cyprosin $B$ during which the $\mathrm{pH}$ and dissolved oxygen concentration were controlled and monitored in

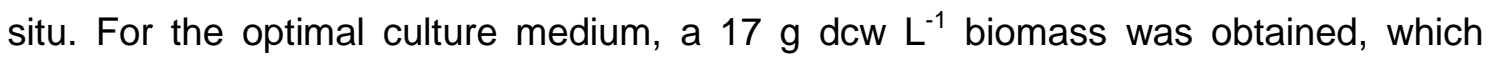
represents a $82 \%$ increase and $2769 \mathrm{U} \mathrm{m}^{-1}$ cyprosin B activity, meaning an increment of $139 \%$ compared to the original fermentation medium or to the culture in bioreactor of S. cerevisiae W303-1A strain [3] (Fig. 2). The secretion rate of active cyprosin B increased $11 \%$ probably due to the culture medium optimization that would have resulted in an improvement in the culture medium performance for enzyme production [33]. This positive evolution achieved may be related to the appropriate growth conditions created inside the bioreactor, such as adequate stirring and homogenization of culture medium, $\mathrm{pH}$ and temperature control, but mainly high dissolved oxygen concentration, which promotes cells growth and, consequently, the enzyme biosynthesis [30,34]. The availability of high amounts of amino acids, co-factors and other non-nutritional trace components present in the bactopeptone and in the YE that are essential for improving cell growth, yeast survival, protein expression and high cell density may also be responsible for a high metabolic rate, leading to an increased expression of recombinant cyprosin B and, consequently, its secretion to the culture medium. 


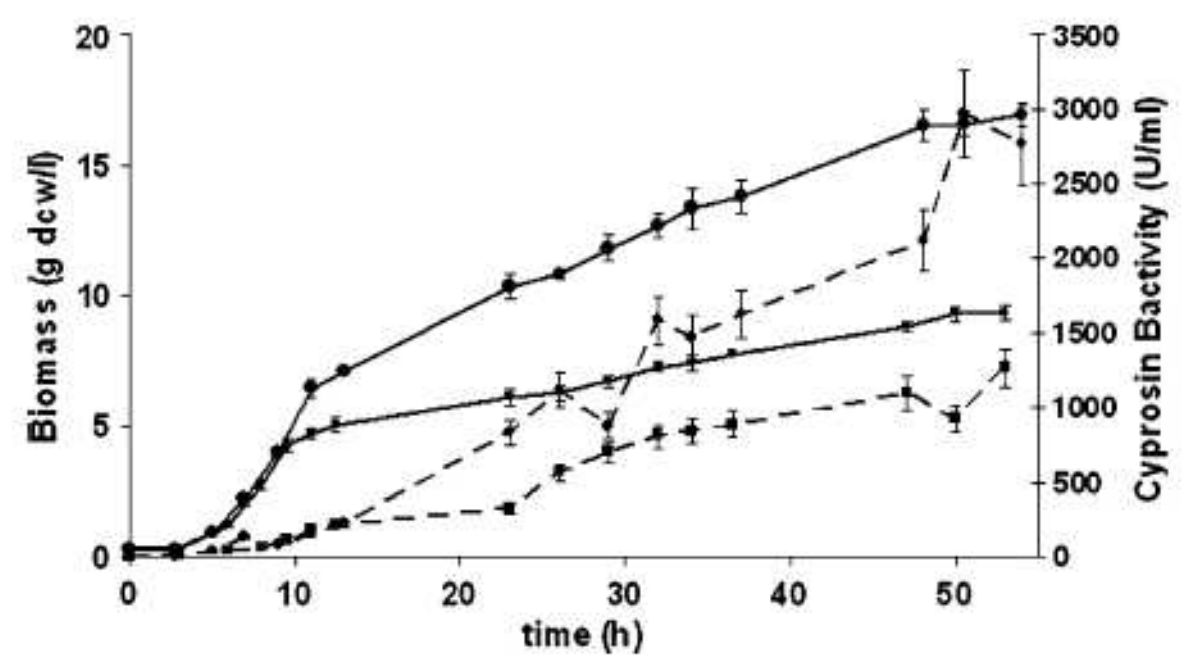

Fig. 2 Evaluation of Saccharomyces cerevisiae BJ1991 strain during cell growth in bioreactor using the optimized culture medium: Full line and circles-Biomass under optimized conditions; Full line and squares-Biomass in non-optimized conditions (control); Dash line and circles-Cyprosin B activity under optimized conditions; Dash line and squares-Cyprosin B activity under non-optimized conditions (control)

The recombinant cyprosin B presents milk-clotting ability similar to cyprosin B from Cynara cardunculus flowers (Fig. $3 a$ and b). The increase in milk-clotting efficiency may result from the increased production of recombinant cyprosin B obtained by culturing the $S$. cerevisiae strain in the culture medium optimized according to the results obtained in this study. It is thus realistic to consider that taking into account the results here described, recombinant cyprosin B can now be produced on a large-scale and may constitute a new and effective alternative for cheese-making enzymes of plant origin. 


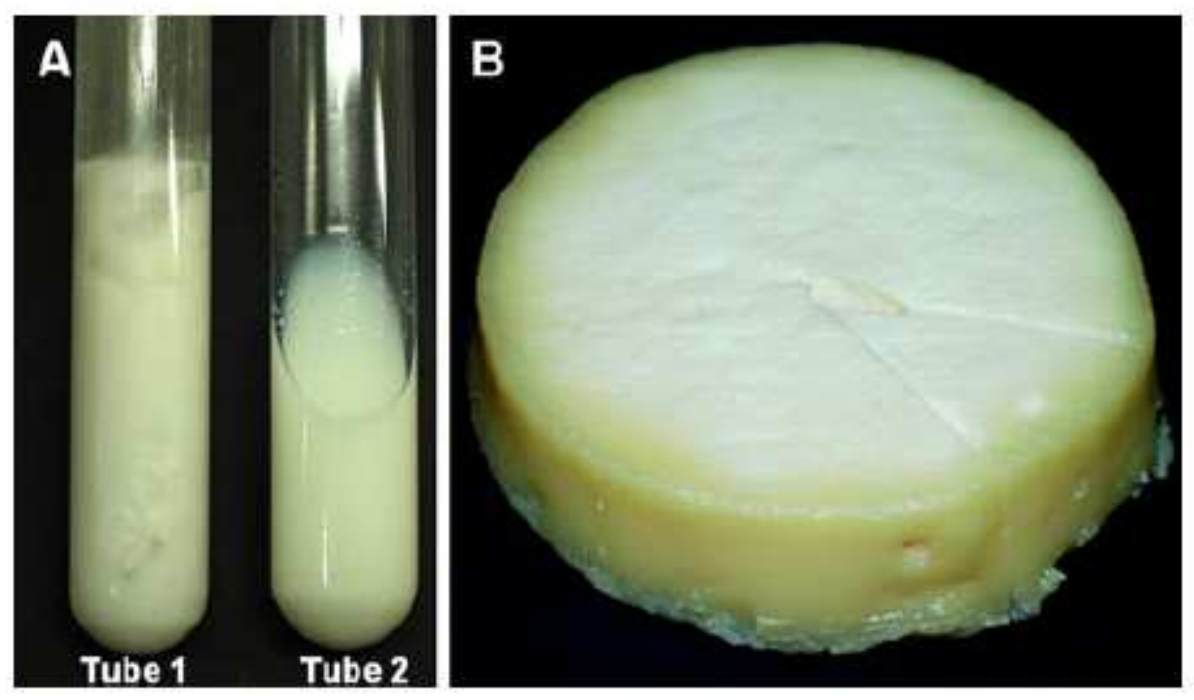

Fig. 3 a Milk clotting using samples of recombinant cyprosin B obtained after fermentation using BJ1991 pCAF15 strain (Tube 2) comparatively with the control (Tube 1 ) without adding recombinant cyprosin B. No curd was formed. b Cheese made with recombinant cyprosin B, presenting high clotting activity, produced in optimized culture medium

\section{Acknowledgments}

We thank Dr. Filomena Calixto for providing S. cerevisiae BJ1991 strain transformed with CYPRO11 gene. PN Sampaio was supported by PRAXIS XXI Ph.D Fellowship (SFRH/BD/8780/2002) from Foundation for Science and Technology, Portugal. L Sousa was supported by the research projects PTDC/ MAT/64353/2006 and FCT/OE. 


\section{References}

1. Cordeiro MC, Jacob E, Kuhn Z, Pais MS, Brodelius PE (1992) Milk clotting and proteolytic activities of purified cynarases from Cynara cardunculus-a comparison to chymosin. Milchwissenschaft 47:683-687

2. Cordeiro MC, Xue ZT, Pietrzak M, Pais MS, Brodelius PE (1994) Isolation and characterization of a cDNA from flowers of Cynara cardunculus encoding cyprosin (an aspartic proteinase) and its se to study the organ-specific expression of cyprosin. Plant Mol Biol 24:733-741

3. Sampaio PN, Fortes AM, Cabral JMS, Pais MS, Fonseca LP (2008) Production and characterization of recombinant cyprosin B in Saccharomyces cerevisiae (W303-1A) strain. J Biosc Bioeng 105:305-312. doi:10.1263/JBB.105.305

4. Swift RJ, Karandikar A, Griffen AM, Punt PJ, Cees AMJJ, Hondel VD, Robson GD, Trinci APJ, Wiebe MG (2000) The effect of organic nitrogen sources on recombinant glucoamylase production by Aspergillus niger in chemostat culture. Fungal Gen Biol 31:125-133. doi:10.1006/fgbi.2000.1241

5. Haq IU, Ali S, Iqbal J (2003) Effects of volume of culture medium on enhanced citric acid productivity by a mutant culture of Aspergillus nıger in stirred fermenter. Lett Appl Microbiol 36:302-306

6. Calado CR, Monteiro SM, Cabral JM, Fonseca LP (2002) Effect of pre-fermentation on the production of cutinase by a recombinant Saccharomyces cerevisiae. J Biosc Bioeng 93:354-359

7. Schneider ALS, Merkle R, Carvalho-Jonas MF, Jonas R, Furlan S (2001) Oxygen transfer on b-D-galactosidase production by Kluyveromyces marxianus using sugar cane molasses as carbon source. Biotechnol Lett 23:547-550

8. Jurado E, Camacho F, Luzo'n G, Vicaria JM (2004) Kinetic models of activity for bgalactosidases: influence of $\mathrm{pH}$, ionic concentration and temperature. Enz Microbial Technol 34:33-40

9. Tari C, Gogus N, Tokatli F (2007) Optimization of biomass, pellet size and polygalacturonase production by Aspergillus sojae ATCC 20235 using response surface methodology. Enz Microbial Technol 40:1108-1116

10. Ooijkaas LP, Wilkinson EC, Tramper J, Buitelaar RM (1999) Medium optimization for spore production of Coniothyrium minitans using statistically-based experimental designs. Biotechnol Bioeng 64:92-100

11. Abdel-Fattah YR, Abdel-Fattah WR, Zamilpa R, Pierce JR (2002) Numerical modelling of ferrous-ion oxidation rate in Acidithiobacillus ferroxidans ATCC 23270: optimization of culture conditions through statistically designed experiments. Acta Microbiol Pol 51:225-235 
12. Adinarayana K, Ellaiah P (2002) Response surface optimization of the critical medium components for the production of alkaline protease by a newly isolated Bacillus sp. J Pharm Sci 5:272-278

13. Liu C, Liu Y, Liao W, Wen Z, Chen S (2003) Application of statistically-based experimental designs for the optimization of nisin production from whey. Biotechnol Lett 25:877-882

14. Ismael A, Soultani S, Ghoul M (1998) Optimization of the enzymatic synthesis of butyl glucoside using response surface methodology. Biotechnol Prog 14:874-878

15. Park YS, Kang SW, Lee JS, Hong SI (2002) Xylanase production in solid state fermentation by Aspergillus niger mutant using statistical experimental designs. Appl Microbiol Biotechnol 58:761-766

16. Mubeccel E, Mutlu SF (2000) Application of a statistical technique to the production of ethanol from sugar beet molasses by Saccharomyces cerevisiae. Biores Technol 73:251-253

17. Oner TE (2006) Optimization of ethanol production from starch by an amylolytic nuclear petite Saccharomyces cerevisiae strain. Yeast 23:849-856

18. Yu X, Hallet SG, Sheppard J, Watson AK (1997) Application of the PlackettBurman experimental design to evaluate nutritional requirements for the production of Colletotrichum coccodes spores. Appl Microbiol Biotechnol 47:301-305

19. Elibol M (2004) Optimization of medium composition for actinorhodin production by Streptomyces coelicolor A3(2) with response surface methodology. Process Biochem 39:1057-1062

20. Gheshlaghi R, Sharer JR, Moo-Young M, Douglas PL (2005) Medium optimization for hen egg white lysozyme production by recombinant Aspergillus niger using statistical methods. Biotechnol Bioeng 90:754-760

21. Rao KJ, Kim C-H, Rhee S-K (2004) Statistical optimization of medium for the production of recombinant hirudin from Saccharomyces cerevisiae using response surface methodology. Process Biochem 35:639-647

22. Liu G-Q, Wang X-L (2007) Optimization of critical medium components using response surface methodology for biomass and extracellular polysaccharide production by Agaricus blazei. Appl Microbiol Biotecnol 74:78-83

23. Ausubel FM, Brent R, Kingston R, Moore DD, Seidenan JG, Smith JA, Struhl K (1997) Current protocols in molecular biology, cap. 13-Saccharomyces cerevisiae. Wiley, USA

24. Bradford MM (1976) A rapid and sensitive method for the quantification of microgram quantities of protein utilizing the principle of protein-dye binding. Anal Biochem 72:248-254 
25. Twining SS (1984) Fluorescein isothiocyanate-labeled casein assay for proteolytic enzymes. Anal Biochem 143:30-34 26. Heimgartner U, Pietrzak M, Geertsen R, Brodelius P, da Silva Figueiredo AC, Pais MS (1990) Purification and partial characterization of milk clotting proteases from flowers of Cynara cardunculus. Phytochemistry 29:1405-1410

27. Berridge NJ (1987) Some observations on the determination of the activity of rennet. Norma FIL-IDF, 110-A. Analyst (London) 77:57-62

28. Box GEP, Wilson KB (1951) On the experimental attainment of optimum conditions. J Royal Stat Soc, B13, New York, USA

29. Khui Al, Cornell JA (1987) Response surfaces: design and analysis. Marcel Dekker, Inc, New York, USA

30. Montgomery DC (1997) Design and analysis of experiments, 4th edn. Wiley, New York

31. Ostergaard S, Olsson L, Nielsen J (2000) Metabolic engineering of Sacharomyces cerevisiae. Microbiol Mol Biol Rev 64:34-50

32. Hahn-Hagerdal B, Karhumaa K, Larsson CU, Gorwa-Grauslund M, Gorgens J, van Zyl W (2005) Role of cultivation media in the development of yeast strains for large scale industrial use. Microbial Cell Fact 31:1-16

33. Makinen V, Haikara A, Enari T-M (1970) Influence of nitrogenous compounds on beer fermentation. Soum Kemistilehti B43:443-447

34. Thomas KC, Hynes SH, Ingledew WM (1994) Effects of particulate materials and osmopotectants on very-high-gravity ethanolic fermentation by Saccharomyces cerevisiae. Appl Environ Microbiol 60:1519-1524 